\title{
Influence of UV Radiation on Mechanical Properties of PVC Composites Reinforced with Pineapple Fiber
}

Masudur Rahman ANM ${ }^{1,2 *}$ and Ruhul A Khan²

${ }^{1}$ Department of Fabric Engineering, Bangladesh University of Textiles, Dhaka, Bangladesh

${ }^{2}$ Polymer Composite Laboratory, Institute of Radiation and Polymer Technology, Bangladesh Atomic Energy Commission, Dhaka, Bangladesh

\begin{abstract}
Pineapple fiber reinforced polyvinyl chloride (PVC) composites (25-75\% fiber by weight) were fabricated using compression molding technique and the mechanical properties such as tensile strength (TS), tensile modulus (TM), bending strength (BS), bending modulus (BM) and impact strength (IS) of the composites were evaluated. It was found that at $55 \%$ fiber content, the composite exhibited the best mechanical properties. The TS, TM, BS, BM and IS were found to be $48.8 \mathrm{MPa}, 773 \mathrm{MPa}, 75.6 \mathrm{MPa}, 4.2 \mathrm{GPa}, 21.4 \mathrm{KJ} / \mathrm{m}^{2}$ for $55 \%$ fiber composite. The composites were exposed to different intensities of ultraviolet (UV) radiation (25-200 UV dose) and found significant improvement in the mechanical properties up to $100 \mathrm{UV}$ dose. At $100 \mathrm{UV}$ dose, the value of TS, TM, BS, BM and IS of the composite were found to be $57.3 \mathrm{MPa}, 932 \mathrm{MPa}, 87.5 \mathrm{MPa}, 5.2 \mathrm{GPa}$ and $26.3 \mathrm{KJ} / \mathrm{m}^{2}$ respectively. Water uptake behaviours of the non-irradiated and UV irradiated composites were also observed. The interfacial property was examined by scanning electron microscopy (SEM).
\end{abstract}

Keywords: Pineapple fiber; Composites; PVC; Mechanical properties; UV radiation

\section{Introduction}

Pineapple fiber is one of the most common well-known natural fibers on the world. Pineapple fiber is extracted from the leaves of the plant Ananus cosomus belonging to the Bromeliaceae family by retting. It is a very cheap and lightweight natural fiber. So, to fabricate partially degradable type, low cost and light weight composite, pineapple fiber was selected. Pineapple leaf fiber has three principle constitutes, namely cellulose (70-82\%) and lignin (5-12\%) [1]. The surface of pineapple fiber is shown in Figures 1 and 2. The superior mechanical properties of pineapple leaf fibers are associated with their high cellulose content. Interest in using natural fibers as reinforcement in the polymer matrix as partial replacement of synthetic fibers has grown significantly during the last era because of their low cost, low abrasive nature and low density, biodegradability and recyclable nature [2-5]. Among the natural fibers, pineapple appears to be a promising material due to its low cost, nonabrasive nature, low density, high strength, and modulus than plastic and is commercially available in tropical countries. Pineapple composites can thus ensure a very effective and value-added application street for the natural fiber. It can be very cost-effective material especially for building and construction industry, packaging, automobile and railway coach interiors, and storage devices $[4,6]$.

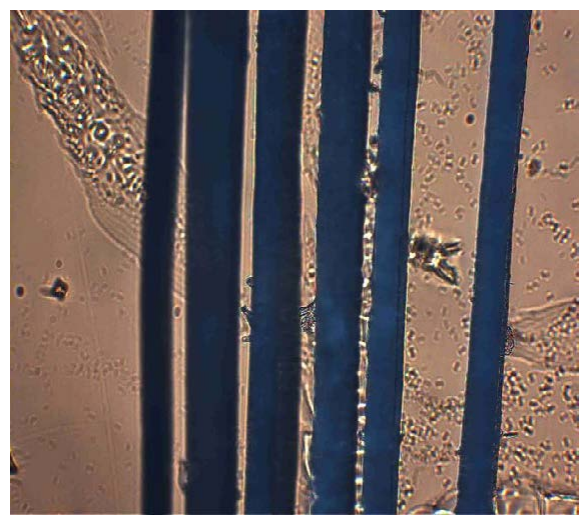

Figure 1: Virgin pineapple fiber (200X view).
Polyvinyl chloride (PVC) is an important engineering thermoplastic which is expansively used in the automobile and building construction fields, as well as packaging due to its outstanding and vital mechanical properties. It has high mechanical strength, high corrosion and chemical resistance, durable, flexible, high softening temperature and relatively low cost. Throughout the world, about $50 \%$ of PVC manufactured is used in the field of construction. But PVC is not biodegradable and today, the world is conscious of the environment. So researches on natural fiber reinforced synthetic polymer-based composites are going

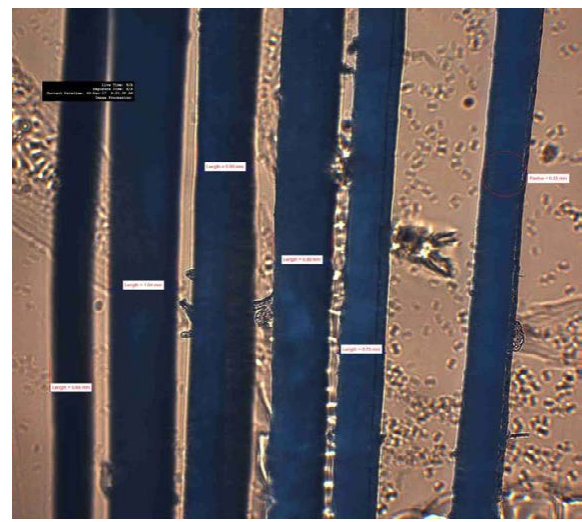

Figure 2: Virgin pineapple fiber (200X view) with the measurement of diameter.

*Corresponding author: Masudur Rahman ANM, Polymer Composite Laboratory, Institute of Radiation and Polymer Technology, Bangladesh Atomic Energy Commission, Dhaka, Bangladesh, Tel: +8801553342607; E-mail: masudfabric@yahoo.com

Received January 22, 2018; Accepted January 27, 2018; Published February 05, 2018

Citation: Masudur Rahman ANM, Khan RA (2018) Influence of UV Radiation on Mechanical Properties of PVC Composites Reinforced with Pineapple Fiber. J Textile Sci Eng 8: 338. doi: 10.4172/2165-8064.1000338

Copyright: (c) 2018 Masudur Rahman ANM. This is an open-access article distributed under the terms of the Creative Commons Attribution License, which permits unrestricted use, distribution, and reproduction in any medium, provided the original author and source are credited. 
on. A good number of papers have been published already on jute fiber reinforced polypropylene, polyvinyl chloride composites. But no studies have been carried out on the mechanical properties of the pineapple fiber reinforced PVC composites $[7,8]$.

There has been increasing significant growth in the development and application of radiation such as UV and gamma in curable materials in various industrial areas. Gamma and UV radiation are known to deposit energy in solid cellulose by Compton scattering and the rapid localization of energy within molecules produced trapped macro cellulosic radicals. The radicals thus created are responsible for changing the physical, chemical and biological properties of cellulose fibers, polymers and composites [9].

The present investigation involves measuring the mechanical properties (tensile, bending and impact strength) of the matrix material PVC and the pineapple fiber/PVC composite. Different intensities of UV radiation were applied to the composite material and the mechanical properties of the composites were evaluated significantly. Water uptake behaviour of the composites was also performed and interfacial properties were investigated by analysis of SEM.

\section{Materials and Methods}

\section{Materials}

Pineapple fiber has been collected from the local market of Bangladesh. Polyvinyl chloride (PVC) was purchased from Polyolefin Company, Private Ltd., and Singapore (Figures 1 and 2).

Composite fabrication: PVC sheet was cut to the desired size (12 $\mathrm{cm} \times 12 \mathrm{~cm}$ ) for composite fabrication. Pineapple fibers were cut into the length of $10 \mathrm{~cm}$. Composites were prepared by sandwiching 4 layers of fiber between 5 sheets of pre-weighted PVC. The sandwich was then placed between two steel molds and heated at $190^{\circ} \mathrm{C}$ for 5 min under a pressure of 5 Metric Ton. Then, the composite containing steel plates was cooled to room temperature using another press (same model) and then cut to the desired size for testing.

Mechanical testing: Tensile tests were evaluated according to DIN 53455 standard method using a Universal Testing Machine (Hounsfield series S, model: H $50 \mathrm{KS}-0404$, UK). The load capacity was $50 \mathrm{KN}$ and a cross-head speed of $10 \mathrm{~mm} / \mathrm{min}$ using gauze length of $20 \mathrm{~mm}$. The dimensions of the test specimen were: $60 \mathrm{~mm} \times 15 \mathrm{~mm} \times 2 \mathrm{~mm}$. Bending tests were carried out according to DIN 53452 using the same testing machine mentioned above at a cross-head speed of $10 \mathrm{~mm} / \mathrm{min}$ and span distance was $40 \mathrm{~mm}$. The impact strength was measured using impact tester (MT-3016, Pendulum type, Germany) according to DIN EN ISO 179 standard in the flat wise, un-notched mode.

Before testing, samples were conditioned at $25^{\circ} \mathrm{C}$ and $50 \%$ relative humidity for several days and all the tests were performed under the same conditions. All the results were taken as the average values of five samples.

Irradiation: The composite samples were subjected to irradiation with UV radiation (254-313 nm) using a minicure (UV Minicure Me200, IST Technik, Germany), which delivers $2 \mathrm{KW}$ power strength. The speed of the conveyor of the Minicure was $4 \mathrm{~m} / \mathrm{min}$ for each pass of the substrate under the lamp by maintaining different UV radiation (25-200 UV pass) intensities. The irradiated samples were subjected for testing after 24 hours of radiation.

Water uptake: Composite samples $\left(20 \times 10 \times 2 \mathrm{~mm}^{3}\right)$ were immersed in a beaker containing deionized water at $25^{\circ} \mathrm{C}$ for different time periods (up to $60 \mathrm{~h}$ ). Before immersion in water, the specimens were dried in an oven at $105^{\circ} \mathrm{C}$, cooled in a desiccator and weighed. After certain periods of time, samples were taken out from the beaker and weighed. Water uptake was determined by the following formula: Water uptake $(\%)=[($ Wwet-Wdry $) /$ Wdry $] \times 100$, where $\mathrm{W}$ dry and $\mathrm{W}$ wet are the weight of the samples before and after water treatment.

SEM analysis: The surface of the composite was examined by Philips SEM at an accelerating voltage of $10 \mathrm{KV}$. SEM specimens were sputter-coated with gold.

\section{Results and Discussions}

\section{Effect of polymer loading}

Mechanical properties of a fiber-reinforced composite depend on several factors, such as fiber content, fiber characteristics, matrix-fiber adhesion and fiber orientation. The fiber content of the composites varied from 25 to $75 \%$ of their total weight. Besides tensile strength is more dependent on the matrix and compatibility between fiber and matrix, while tensile modulus is more influenced by the fiber impregnation and fiber ratio. Effect of fiber loading (wt \%) on the mechanical properties of resulting composites was studied and the results are given in Figures 3-5.

It was found from the figures that TS, BS, TM, BM and IS were

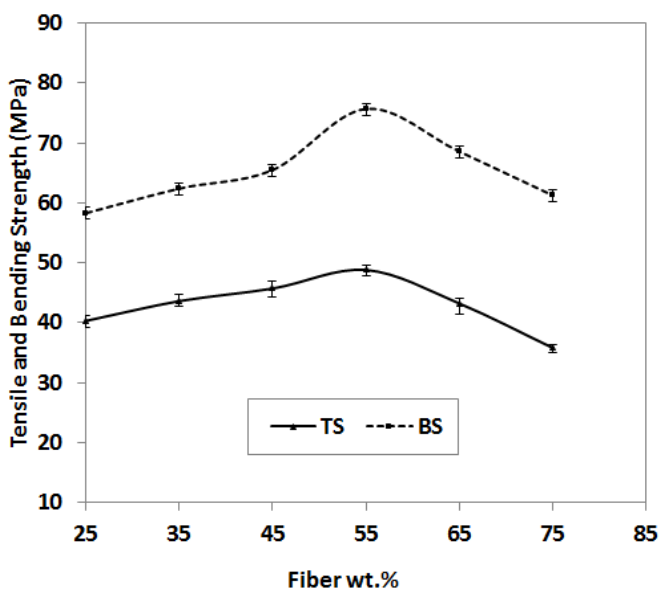

Figure 3: Effect of polymer loading on tensile and bending strength of the composites

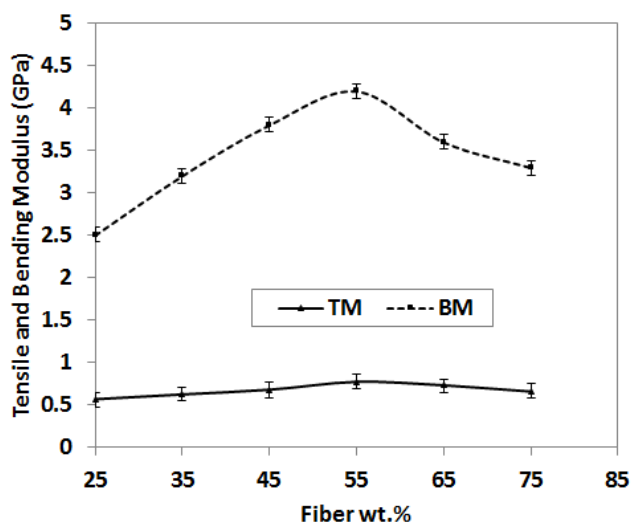

Figure 4: Effect of polymer loading on tensile and bending modulus of the composites. 


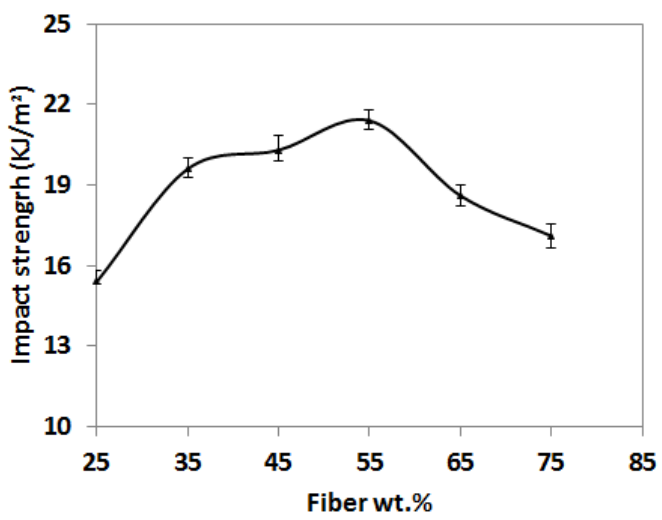

Figure 5: Effect of polymer loading on impact strength of the composites.

\begin{tabular}{|c|c|c|c|c|c|}
\hline \multicolumn{5}{|c|}{$\begin{array}{c}\text { Tensile, bending and impact properties of PVC sheet and composites (55\% } \\
\text { fiber by weight) }\end{array}$} \\
\hline & \multicolumn{3}{|c|}{ Tensile properties } & Bending properties \\
\hline Materials & TS (MPa) & TM (MPa) & IS (KJ/m²) & BS (MPa) & BM (GPa) \\
\hline PVC sheet & $34.2 \pm 1.2$ & $528 \pm 10$ & $4.5 \pm 0.4$ & $40.7 \pm 1.6$ & $1.2 \pm 0.4$ \\
\hline Pineapple/PVC & $48.8 \pm 1.5$ & $773 \pm 13$ & $21.4 \pm 0.5$ & $75.6 \pm 1.8$ & $4.2 \pm 0.7$ \\
\hline
\end{tabular}

Table 1: Tensile, bending and impact properties of PVC sheet and composites (55\% fiber by weight).

increased linearly with increasing the percentage of fiber up to $55 \%$ in the composite and then started decreasing with the increase in fiber loading. At 55\% fiber content, TS, BS, and IS of the composites were found to be $48.8 \mathrm{MPa}, 75.6 \mathrm{MPa}$ and $21.4 \mathrm{KJ} / \mathrm{m}^{2}$ respectively. It was also found that the value of TM and $\mathrm{BM}$ were $773 \mathrm{MPa}$ and $4.2 \mathrm{GPa}$, respectively. So, the mechanical properties of the composites increased with the increase of fiber in composites up to $55 \%$ by weight and above $55 \%$, the mechanical properties decrease with the increase of fiber loading which may be attributed to the fact that increasing fiber content in the composites decreased the fiber-matrix adhesion due to poor wetting tension. From this investigation, this is clear that $55 \%$ fiber content composites performed the best mechanical properties. So the composition of 55\% fiber content was taken to be the optimum composition. At lower levels of fiber content, the composite shows poor mechanical properties due to reduced fiber population and little load transmission capacity to one another. As a result, stress gets accumulated in certain points of the composites and highly localized strain occurred in the matrix. At the levels of 55\% fiber loading, the population of the fibers is just right for maximum orientation and the fibers actively participate in stress transfer from the continuous polymer matrix to the dispersed fiber phase $[5,10]$ (Figure 4).

Above 55\% fiber content, there was a notable reduction in mechanical properties of the composites. Higher level of fiber content increased the population of fibers, which may lead to cluster and stress transfer becoming blocked which could cause crack initiation as a result failure occurs. The failure of the bio-composite might be initiated by the failure of the matrix and then followed by fiber breakage [11] (Figure 5).

\section{Comparative mechanical properties}

The mechanical properties such as tensile, bending, and impact strength of PVC sheet and Pineapple/PVC (55\% fiber by wt.) composites were evaluated and compared. The results are presented in Table 1.
From Table 1, it was found that TS, TM, BS, BM, and IS of the PVC sheet was found to be $34.2 \mathrm{MPa}, 528 \mathrm{MPa}, 40.7 \mathrm{MPa}, 1.2 \mathrm{GPa}, 4.5 \mathrm{KJ} / \mathrm{m}^{2}$ respectively. Virgin pineapple fibers successfully reinforced with PVC matrix. The TS and TM of the composite increased to 42.7 and $46.4 \%$, respectively than that of the matrix PVC. It was found that BS, BM and IS also improved $85.7,250$ and $377.7 \%$, respectively over the matrix material PVC.

\section{Effect of UV radiation on mechanical properties of the composites}

The optimized composite samples ( $55 \%$ fiber by wt.) were irradiated by different dose of UV radiation. The effects of UV radiation on the mechanical properties of composites such TS, TM, BS, BM and IS of the composites were investigated. The tensile, bending and impact strength as a function of total dose of the composites are shown in Figures 6-8.

From Figures 6-8, it was found that the TS, TM, BS, BM and IS of the composites increasing trend from 25-100 UV dose and after that the values decrease up to $200 \mathrm{UV}$ dose. Best mechanical properties were obtained using $100 \mathrm{UV}$ dose and the value of TS, TM, BS, BM and IS of composite were found to be $57.3 \mathrm{MPa}, 932 \mathrm{MPa}, 87.5 \mathrm{MPa}, 5.2 \mathrm{GPa}$ and $26.3 \mathrm{KJ} / \mathrm{m}^{2}$ respectively. For the composite, about $17.4 \%$ increase in TS,

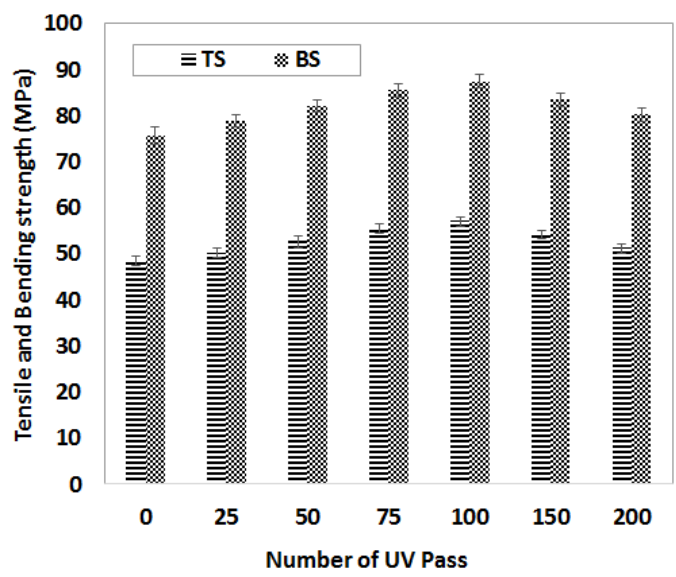

Figure 6: Tensile and bending strength of UV irradiated composites against total radiation dose.

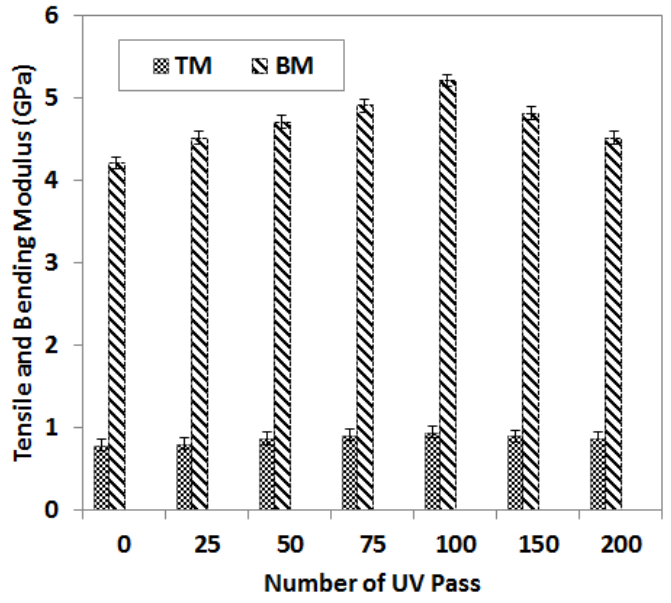

Figure 7: Tensile and bending modulus of UV irradiated composites against total radiation dose. 
$20.5 \%$ increase in TM, $15.7 \%$ increase in BS, $23.8 \%$ increase in BM and $22.8 \%$ increase in IS was found compared to non-irradiated sample. This is significant findings in this research work (Figure 7).

TS, TM, BS, BM and IS of the composite are influenced by the interfacial bond strength of the PVC matrix and fiber. UV treatment improved interfacial bond strength by producing active sites. Consequently, the mechanical properties of the irradiated composites were improved up to $100 \mathrm{UV}$ dose due to inter cross-linking between the neighboring cellulose molecules. It can be assumed that stress transfer between matrix and fiber was good at $100 \mathrm{UV}$ dose leading to cracks preventing at the fiber. But above $100 \mathrm{UV}$ dose, the main chain may be broken down and polymer may be degraded into fragments and as a result, the mechanical properties are degraded. UV irradiation affects the polymeric structure of the cellulose fiber and produces active sites that increase the intra-chain bond in the fiber that causes the polymeric chain to group together in a highly ordered (crystal-like) structure. The intra-chain bonds are strong and give the fiber strength [11-14]. For these reasons, the mechanical properties of the irradiated composite increased up to $100 \mathrm{UV}$ dose (Figure 8).

\section{Water uptake of the composites}

Water uptake determines the water-swelling behaviour of the samples. The results of water uptake (\%) of non-irradiated and irradiated samples were shown in Figure 9 against the time (h) of

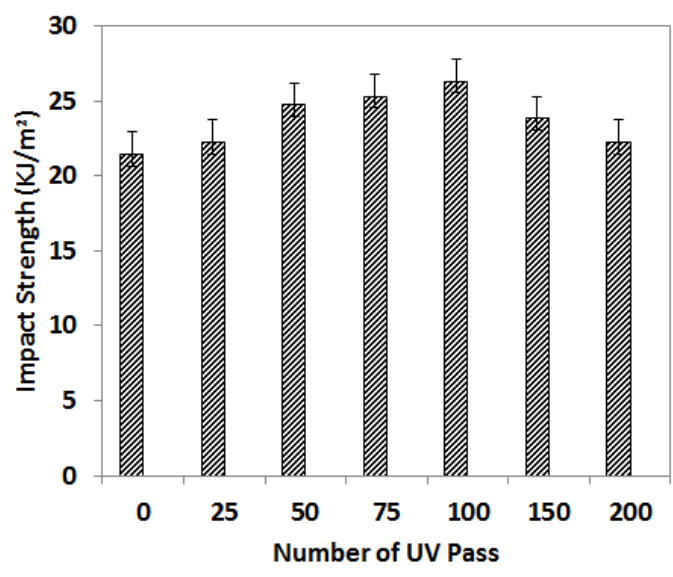

Figure 8: Impact strength of UV irradiated composites.

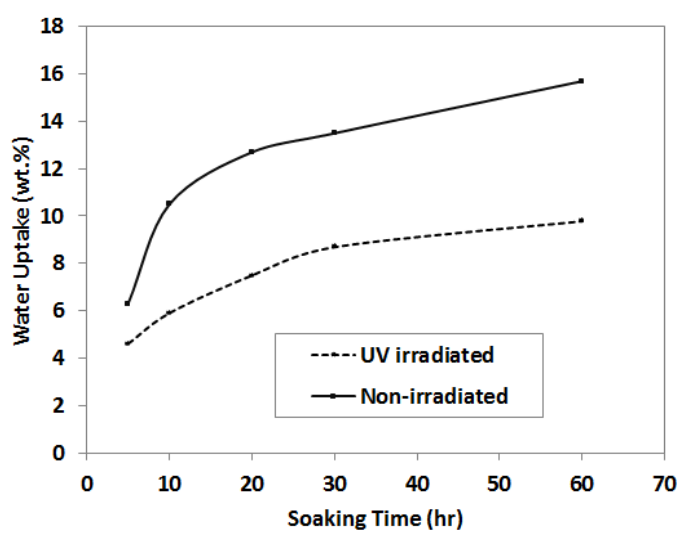

Figure 9: Water uptake behaviour of non-irradiated and UV irradiated composites.

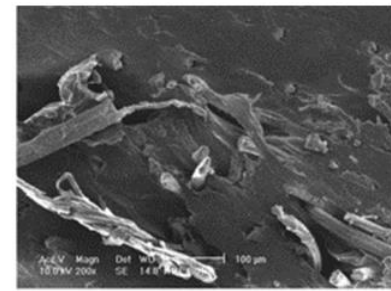

(a)

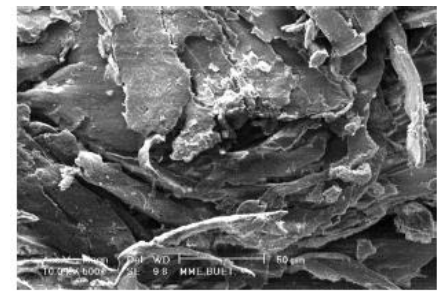

(b)
Figure 10: SEM image of the surfaces (a) tensile fracture surface (b) of Pineapple/PVC composite.

soaking in water. The water uptake values were found (6.3-15.7\%) for non-irradiated composite, and (4.6-9.8\%) for UV irradiated composite at various soak time. The water absorption by the samples was very fast within the initial $10 \mathrm{~h}$, and then the absorption rate became slow. Hydroxyl groups present in the cellulose form intermolecular hydrogen bonds with other cellulose molecules as well as with other hydrogen groups and increase moisture absorption (Figure 9).

The water uptake value of UV treated composites was found to lower than other composites ascribed that using UV decreased the $\mathrm{OH}$ group as well as increased crystallinity in cellulosic fiber by grafting in the polymer chain which in turns decrease amorphous regions.

\section{Morphological study of the composites}

Scanning electron microscopy (SEM) was used to study the interfacial properties of the composites. (Figure 10a and 10b) shows the surface and tensile fracture surface of pineapple fiber composites.

It is observed that the diameters of the fibers are different and the surface of the fibers is rough with the adhesion of some smaller fibers and particles. On the contrary, the pineapple fiber was completely surrounded with the PVC matrix proving a better fiber-matrix adhesion which leads to better stress transfer between the matrix and the reinforcing fibers.

\section{Conclusion}

Pineapple fiber reinforced PVC based composites were prepared successfully using compression molding and physico-mechanical properties were evaluated. The investigation showed that at $55 \%$ fiber content the composite showed optimum mechanical properties. $\mathrm{UV}$ radiation was also found to be a potential source to improve the physico-mechanical properties of Pineapple/PVC composites. SEM analysis showed that fiber and PVC matrix was in good adhesion, but also revealed that the interfacial bonding between fiber and polymer can be further improved by using coupling agent or surface treatment of fibers.

\section{References}

1. Arib R, Sapuan S, Ahmad M, Paridah M, Zaman HK (2006) Mechanical properties of pineapple leaf fibre reinforced polypropylene composites. Materials \& Design 27: 391-396.

2. Rahman N, Khan MA, Khan RA, Chowdhury TA (2011) Modification of gelatin films using trimethylolpropane trimethacrylate (TMPTMA) by photo-curing. Poly Plast Tech and Engg 50: 404-11.

3. Khan RA, Khan MA, Das AK, Debnath KK, Dey K, et al. (2010) Thermomechanical and interfacial properties of calcium alginate fiber-reinforced linear low-density polyethylene composite. Poly Plast Tech Engg 49: 602-608.

4. Dong C, Lu Z, Zhang X, Zhu P, Li N (2014) The preparation and dyeing properties of pineapple leaf fibres modified with a cationic modifier. Color Tech 130: $260-5$. 
Citation: Masudur Rahman ANM, Khan RA (2018) Influence of UV Radiation on Mechanical Properties of PVC Composites Reinforced with Pineapple Fiber. J Textile Sci Eng 8: 338. doi: 10.4172/2165-8064.1000338

5. Kaewpirom S, Worrarat C (2014) Preparation and properties of pineapple leaf fiber reinforced poly (lactic acid) green composites. Fibers and Polymers 15 $1469-1477$.

6. Siregar JP, Sapuan S, Rahman M, Zaman H (2010) The effect of electron beam irradiation on the mechanical properties of pineapple leaf fibre (PALF) reinforced high impact polystyrene (HIPS) composites. Mater Sci and Engg: IOP Publishing.

7. Khan RA, Khan MA, Zaman HU, Parvin F, Islam T, et al. (2012) Fabrication and characterization of jute fabric-reinforced PVC-based composite. Journal of Thermoplastic Composite Material 25: 45-58

8. Khan RA, Zaman HU, Khan MA, Nigar F, Islam T, et al. (2010) Effect of the Incorporation of PVC on the Mechanical Properties of the Jute-Reinforced LLDPE Composite. Polym Plast Tech and Engg 49: 707-712.

9. Poddar P, Arafat $Y$, Dey K, Khan R, Chowdhury AS (2016) Effect of y radiation on the performance of jute fabrics-reinforced urethane-based thermoset composites. J Thermoplast Comp Mater 29: 508-518.
10. Siregar JP, Cionita T, Bachtiar D, Ruzaimi M, Rejab M (2015) Tensile properties of pineapple leaf fibre reinforced unsaturated polyester composites. Applied Mechanics and Materials 695: 159-62.

11. Islam $T$, Khan RA, Khan MA, Rahman MA Fernandez-Lahore $M$, Huque $Q$ (2009) Physico-mechanical and degradation properties of gamma-irradiated biocomposites of jute fabric-reinforced poly (caprolactone). Poly Plast Tech and Eng 48: 1198-1205.

12. Roy JK, Akter N, Zaman HU, Ashraf K, Sultana S, et al. (2014) Preparation and properties of coir fiber-reinforced ethylene glycol dimethacrylate-based composite. J Thermoplast Comp Mater 27: 35-51.

13. Khan A, Hossain M, Khan MA, Khan RA, Hakim M (2010) Effect of ultraviole radiation on the mechanical and dielectric properties of Hessian cloth/PP composites with starch. Poly Plast Tech and Engg 49: 757-65.

14. Zaman HU, Khan A, Hossain M, Khan MA, Khan RA (2009) Mechanical and electrical properties of jute fabrics reinforced polyethylene/polypropylene composites: role of gamma radiation. Poly Plast Tech and Engg 48: 760-766. 